Jurnal Ilmu Ilmu Agribisnis: Journal of Agribusiness Science, 9(1), Februari 2021

\title{
PARTISIPASI PETANI ANGGOTA P3A DALAM PENGELOLAAN AIR DI DESA BANDAN HURIP DAN PALAS JAYA, KECAMATAN PALAS KABUPATEN LAMPUNG SELATAN
}

\author{
(The Participation of Farmers of P3A Members in Irrigation Water Management in Bandan Hurip and Palas \\ Jaya Village, Palas, South Lampung District)
}

Muhammad Faiq Saputra, Dewangga Nikmatullah, Muhammad Ibnu

Jurusan Agribisnis, Fakultas Pertanian, Universitas Lampung, Jl. Prof. Dr. Soemantri Brodjonegoro No.1 Bandar Lampung 35141, e-mail: dewangga.nikmatullah@fp.unila.ac.id

\begin{abstract}
This study aims to analyze the level of participation of P3A member farmers in irrigation water management, to find out the variables that affect the level of the participation, and to find out the implications of research findings on irrigation water management. The research location was chosen deliberately in the villages of Bandan Hurip and Palas Jaya, Palas Subdistrict, South Lampung Regency. The research was carried out in June 2018 using a survey method. The number of respondents was 82 P3A members determined using the Slovin formula. The level of participation of P3A members was analyzed descriptively, the variables affecting the level of the participation were analyzed using ordinal logistic regression, and the implications of the research findings were analyzed using qualitative descriptive analysis. The results showed that the highest level of participation of P3A members in water management was 43.90 percent at the low classification level. The variables that influence the level of the participation in irrigation water management are the member interaction and the members' motivation, while variables that do not affect are the group's role, level of knowledge, and members' activity.
\end{abstract}

Key words: participation, P3A, water management

\section{PENDAHULUAN}

Produksi padi di Provinsi Lampung belum mencapai target yang telah ditetapkan oleh Kementerian Pertanian. Hasil panen padi di Provinsi Lampung pada tahun 2017 adalah sebesar 4.090.654 ton. Hasil panen padi tersebut belum memenuhi target Kementerian pertanian yaitu sebesar 4.300.000 ton (Hafif 2016). Daerah penghasil padi di Provinsi Lampung perlu berkontribusi untuk memenuhi target tersebut, termasuk Kabupaten Lampung Selatan. Namun, produktivitas padi di Kabupaten Lampung Selatan mengalami penurunan.

Salah satu sentra produksi padi di Provinsi Lampung adalah Kabupaten Lampung Selatan. Kabupaten Lampung Selatan memproduksi padi sebesar 527.166 ton pada tahun 2017 (BPS 2018). Produksi tersebut menyumbang 21,56 persen dari total produksi Provinsi Lampung. Produktivitas padi di Kabupaten Lampung Selatan mengalami penurunan dari 5,47 ton per hektar menjadi 5,46 ton per hektar di tahun 2017.

Padi memerlukan air dalam jumlah yang cukup agar dapat berproduksi secara optimal.
Kekurangan air pada tanaman padi dapat mengakibatkan padi menderita cekaman air (water stress). Water stress pada taman padi menyebabkan daun padi menggulung, anakan padi berkurang, pembungaan tertunda, dan biji menjadi hampa. Tanaman padi memerlukan air dengan jumlah yang cukup dan waktu yang tepat pada setiap fase pertumbuhannya. Pengurangan jumlah air yang berlebih pada tanaman padi pada waktu tertentu dapat di kurangi melalui drainase (Taufik, Arafah, Nappu dan Fadjry 2014). Kebutuhan air sulit dikontrol dengan mengandalkan air hujan sehingga suplai air irigasi menjadi sangat penting.

Partisipasi masyarakat dibutuhkan dalam menjalankan pengelolaan jaringan irigasi. Tanggung jawab pengelolaan jaringan irigasi tersier dan jaringan irigasi kwarter sampai di tingkat usahatani adalah tanggung jawab dan hak petani yang terhimpun dalam wadah perkumpulan petani pemakai air. Jaringan irigasi tersier adalah saluran yang membawa air dari sadap tersier di jaringan utama ke dalam petak tersier lalu ke saluran kuarter. Saluran kuarter adalah saluran yang membawa air dari boks bagi kuarter melalui bangunan sadap tersier ke sawah-sawah (UU No 7) Tahun 2004 tentang Sumberdaya dan PP No.20 
tahun 2006 Tentang Irigasi). Kecamatan Palas merupakan Kecamatan yang memiliki luas lahan dan produksi padi terbesar di Kabupaten Lampung Selatan. Kecamatan Palas memproduksi padi sebesar 97.060 ton pada tahun 2017 (BPS 2018). Sebagai kontributor produksi padi di Kabupaten Lampung Selatan, Kecamatan Palas mengalami penurunan produktivitas padi dari 5,62 ton perhektar pada 2016 menjadi 5,49 ton perhektar pada tahun 2017. Desa di Kecamatan Palas yang memiliki irigasi teknis yaitu Desa Sukaraja, Desa Sukamulya, Desa Palas Jaya, Desa Bandan Hurip, Desa Pulau Tengah. Desa Bandan Hurip merupakan desa dengan saluran irigasi terpanjang, sedangkan Desa Palas Jaya merupakan desa dengan tingkat ketergantungan saluran irigasi teknis yang tinggi (BPP Kecamatan Palas 2017).

Desa Bandan Hurip dan Desa Palas Jaya memiliki P3A dalam pengelolaan air irigasi. P3A Desa Bandan Hurip dan Palas Jaya membutuhkan partisipasi masyarakat untuk menghasilkan pengelolaan irigasi yang baik. Pengelolaan irigasi air yang tidak baik akan menurunkan produksi dan produktivitas padi. Partisipasi petani anggota P3A yang buruk dalam pengelolaan air irigasi diduga dapat menurunkan produktivitas padi. Partisipasi masyarakat dalam pengelolaan air irigasi meliputi beberapa aspek mulai dari perencanaan pengelolaan, pelaksanaan pengelolaan, penilaian atau evaluasi pengalolaan (Ibrahim, Wangke dan Memah 2017).

Penelitian ini menggunakan implikasi dalam tujuan penelitiannya Penggunaan implikasi dalam penelitian ini di harapkan dapat menghasilkan saran kebijakan serta setrategi yang relevan bagi anggota P3A Desa Bandan Hurip dan Desa Palas Jaya. Tujuan dari penelitian ini yaitu menganalisis tingkat partisipasi petani anggota P3A dalam pengelolaan air irigasi, mengetahui variabel apa yang mempengaruhi tingkat partisipasi petani anggota P3A dalam pengelolaan air di Desa Bandan Hurip dan Palas Jaya.

\section{METODE PENELITIAN}

Metode penelitian yang digunakan adalah metode survei. Penentuan lokasi penelitian dipilih secara sengaja (purposive), yaitu di P3A Maju Bersama Desa Bandan Hurip dan P3A Maju Jaya Desa Palas Jaya Kecamatan Palas. Adapun pertimbangan dalam penentuan lokasi penelitian ini yaitu:

1. Melihat kenyataan bahwa Kecamatan Palas menjadi penghasil produksi dan produktifitas padi terbesar di Lampung Selatan dan daerah yang melakukan kegiatan pengelolaan irigasi untuk usahatani padi.

2. P3A Maju Bersama merupakan kelompok P3A yang melakukan pengelolaan irigasi P3A dengan sawah teknis terluas.

3. P3A Maju Jaya merupakan kelompok P3A yang melakukan pengelolaan irigasi $\mathrm{P} 3 \mathrm{~A}$ dengan ketergantungan atas sawah teknis yang besar

Penelitian ini menggunakan data primer dan sekunder. Data primer diperoleh langsung dari 82 anggota P3A Maju Bersama Desa Bandan Hurip , dan P3A Maju Jaya Desa Palas Jaya yang terpilih menjadi responden. Data sekunder diperoleh dari Balai Penyuluhan Pertanian Perikanan dan Kehutanan (BP3K) Kecamatan Palas, Dinas Tanaman Pangan dan Hortikultura Kabupaten Lampung Selatan, Badan Pusat Statistik (BPS), serta lembaga atau instansi terkait yang dapat dipercaya. Metode analisis data yang digunakan pada penelitian ini yaitu menggunakan analisis deskriptif kualitatif dan kuantitatif. Analisis deskriptif kualitatif bertujuan untuk mengetahui klasifikasi tingkat partisipasi petani anggota P3A dalam pengelolaan air irigasi. Analisis kuantitatif bertujuan untuk mengetahui variabel-variabel yang memengaruhi tingkat partisiasi petani anggota $\mathrm{P} 3 \mathrm{~A}$ dalam pengelolaan air irigasi, menggunakan analisis regresi ordinal logit.

Analisis yang digunakan untuk menjawab tujuan pertama adalah analisis deskriptif kualitatif. Data -data yang di dapat disusun menjadi suatu narasi yang dapat menggambarkan tingkat partisipasi anggota P3A dalam pengelolaan air irigasi. Partisipasi petani anggota P3A dalam pengelolaan air dapat dilihat melalui 3 tahapan partisipasi yang meliputi partisipasi dalam perencanaan kegiatan, partisipasi dalam pelaksanaan kegiatan dan partisipasi dalam penilaian atau evaluasi.

Analisis yang digunakan untuk menjawab tujuan kedua adalah analisis regresi ordinal logit. analisis ini di gunakan untuk mengetahui variabel- variabel yang mempengaruhi tingkat partisipasi petani anggota P3A dalam pengelolaan air. Variabelvariabel nya antara lain interaksi anggota P3A $\left(\mathrm{X}_{1}\right)$, keterlibatan anggota $\mathrm{P} 3 \mathrm{~A}\left(\mathrm{X}_{2}\right)$, tingkat pengetahuan anggota $\left(\mathrm{X}_{3}\right)$, motivasi anggota $\left(\mathrm{X}_{4}\right)$ dan keaktifan anggota $\left(\mathrm{X}_{5}\right)$. Model logit dinyatakan sebagai :

$$
\begin{aligned}
& \mathrm{Pi}=\mathrm{F}(\mathrm{Zi})=\mathrm{F}\left(\alpha+\beta \mathrm{X}_{\mathrm{i}}\right) \\
& \mathrm{Pi}=1 /\left(1+\mathrm{e}^{\mathrm{Zi}}\right) \\
& \mathrm{Pi}=1 /\left(1+\mathrm{e}^{-\left(\alpha+\beta X_{i}\right)}\right) \ldots \ldots \ldots
\end{aligned}
$$


Jika kedua sisi persamaan dikalikan $1+\mathrm{e}^{\mathrm{Zi}}$ maka diperoleh :

$\left(1+\mathrm{e}^{\mathrm{Zi}}\right) \mathrm{Pi}=1$

$\mathrm{e}-{ }^{\mathrm{Zi}}=1 / \mathrm{Pi}-1=\left[\frac{\mathrm{pi}}{1-\mathrm{p}}\right]$

Karena e-Zi $=1 /$ e $^{\text {Zi }}$ maka:

$\mathrm{e}-{ }^{\mathrm{Zi}}=\frac{\mathrm{pi}}{1-\mathrm{pi}}($ Rasio Odds $)$

Faktor-faktor yang memengaruhi tingkat partisipasi anggota $\mathrm{P} 3 \mathrm{~A}$ digunakan analisis regresi logistik dengan model sebagai berikut :

$\begin{aligned} \mathrm{Z}_{\mathrm{i}}= & \operatorname{Ln}\left[\frac{\mathrm{pi}}{1-\mathrm{pi}}\right]=\alpha+\beta_{1} \mathrm{X}_{1}+\beta_{2} \mathrm{X}_{2}+\beta_{3} \mathrm{X}_{3}+\beta_{4} \mathrm{X}_{4} \\ & +\beta_{5} \mathrm{X}_{5}+\mathrm{e} \ldots \ldots \ldots \ldots \ldots \ldots \ldots \ldots \ldots \ldots \ldots \ldots \ldots \ldots \ldots \ldots \ldots \ldots \ldots \ldots \ldots\end{aligned}$

Keterangan:

$\mathrm{Zi}:$ Probabilitas,

$\mathrm{Pi} \quad$ : $\mathrm{P}(\mathrm{Y}=1)$ jika partisipasi tinggi

$\mathrm{Pi} \quad: \quad \mathrm{P}(\mathrm{Y}=0)$ jika lainnya

$\alpha \quad:$ Intersep

$\beta_{1}-\beta_{5}:$ Koefisien variabel bebas

$\mathrm{X}_{1}$ : Interaksi anggota P3A

$\mathrm{X}_{2}$ : Keterlibatan anggota P3A

$\mathrm{X}_{3}$ : Tingkat pengetahuan anggota

$\mathrm{X}_{4} \quad$ : Motivasi anggota

$\mathrm{X}_{5}$ : Keaktifan anggota

Etimasi model logit dengan melakukan uji serentak yaitu dengan menggunakan Likelihood Ratio (LR). Likelihood Ratio (LR) setara dengan F-stat yang berfungsi untuk menguji apakah semua slope koefisien regresi variabel independen secara bersama-sama mempengaruhi variabel dependen (Widarjono 2010).

Hipotesis dalam pengujian Likelihood Ratio ialah:

$\mathrm{H}_{0}$ : Semua variabel independen secara bersama sama tidak mempengaruhi variabel dependen

$\mathrm{H}_{1}$ : Semua variabel independen secara serentak mempengaruhi variabel dependen

$\mathrm{H}_{0}$ ditolak jika Probability Likelihood Ratio $<\alpha$, dan $\mathrm{H}_{0}$ diterima jika Probability Likelihood Ratio> $\alpha$. Selanjutnya, dilakukan uji parsial (Zstat) yaitu dengan menggunakan Wald Test. Hipotesis dalam pengujian Wald Test adalah:

$\mathrm{H}_{0}$ : variabel independen yang diuji secara individu tidak berpengaruh nyata terhadap variabel dependen
$\mathrm{H}_{1}$ : variabel independen yang diuji secara individu berpengaruh nyata terhadap variabel dependen

$\mathrm{H}_{0}$ ditolak jika Probability Wald $<\alpha$, dan $\mathrm{H}_{0}$ diterima jika Probability Wald $>\alpha$. Untuk melihat seberapa baik model dapat menjelaskan pengaruh antara variabel dependen dengan independennya dilakukan uji Goodness Of Fit. Pada regresi logistik, koefisien determinasi $\left(\mathrm{R}^{2}\right)$ yang digunakan adalah Nagelkerke $R$ Square, yaitu $R$-square tiruan.

Analisis yang digunakan untuk menjawab tujuan ketiga adalah analisis deskriptif kualitatif bedasarkan data yang diperoleh dari hasil regresi logistik pada tujuan pertama dan tujuan kedua.

\section{HASIL DAN PEMBAHASAN}

Tingkat Pertisipasi Petani Anggota P3A dalam Pengelolaan Air di Desa Bandan Hurip dan Palas Jaya Kecamatan Palas Kabupaten Lampung Selatan

Partisipasi adalah keterlibatan atau keikutsertaan seorang atau sekelompok anggota masyarakat dalam suatu kegiatan atau pembangunan. Menurut Ndraha (1990) tingkat partisipasi dapat di bedakan menjadi tiga yaitu tingkat partisipasi tinggi, tingkat partisipasi sedang dan tingkat partisipasi rendah. Ada tiga tahap kegiatan dalam partisipasi yaitu partisipasi dalam perencanaan, partisipasi dalam pelaksanaan dan partisipasi dalam penilaian.

\section{Partisipasi Anggota P3A dalam Perencanaan Kegiatan Pengelolaan Air Desa Bandan Hurip dan Palas Jaya Kecamatan Palas Kabupaten Lampung Selatan}

Partisipasi anggota P3A dalam perencaanaan di nilai dari keikutsertaan anggota P3A dalam mengikuti pertemuan, keikut sertaan anggota $\mathrm{P} 3 \mathrm{~A}$ dalam mengikuti pertemuan atau rapat perencanaan penentuan lokasi jaringan air irigasi, keikutsertaan anggota dalam perencanaan pola tanam pada pengelolaan air irigasi, keikutsertaan anggota P3A dalam perencanaan kegiatan pembagian atau penjadwalan pemberian air irigasi, keikut sertaan anggota P3A dalam perencanaan kegiatan pemeliharaan jaringan irigasi. Partisipasi anggota P3A dalam perencanan kegiatan diklasifikasikan dengan membagi menjadi tiga kelas yaitu rendah, sedang, tinggi. 
Tabel 1. Partisipasi anggota P3A dalam tahap perencanaan

\begin{tabular}{lcccc}
\hline \multicolumn{2}{c}{ Selang } & Klasifikasi & $\begin{array}{c}\text { Jumlah } \\
\text { Anggota }\end{array}$ & Persentase \\
\hline 0,000 & 3,491 & Rendah & 37 & 45,12 \\
3,492 & 6,983 & Sedang & 31 & 37,80 \\
6,984 & 10,475 & Tinggi & 14 & 17,07 \\
\hline Jumlah & & 82 & $100 \%$ \\
\hline
\end{tabular}

Tabel 1 menunjukan bahwa sebaran partisipasi petani anggota P3A dalam tahap perencannaan kegiatan pengelolaan air sebagian besar berada di kelasifikasi tinggi yaitu sebesar 45,12 persen. Hal ini menunjukan bahwa sebagian besar responden anggota P3A melaksanakan rapat perencanaan pengelolaan air irigasi, dengan mengikuti rapat atau musyawarah perencanaan pengelolaan air yang meliputi perencanaan penentuan lokasi jaringan air irigasi, perencannaan pola tanam, perencanaan kegiatan pembagian atau penjadwalan pembarian air irigasi, perencanaan kegiatan pemeliharaan jaringan irigasi. Responden anggota P3A sebagian besar hadir 4 kali dari 8 kali pertemuan yang di rencanakan. Proses penyusunan perencanaan pengajuan proposal sebagian besar dilaksanakan oleh pengurus P3A. Walau tingkat kehadiran pada tahap perencanaan tergolong tinggi yaitu sebesar 45,12 persen terdapat responden anggota P3A yang masih belum hadir pada rapat atau pertemuan perencanaan pengelolaan air, seperti alasan pribadi anggota yang mengerjakan pekerjaan lain, serta kurangnya pendampingan yang dilakukan oleh penyuluh dan pengurus P3A terhadap anggota, sehingga sebagian anggota P3A tidak ikut dalam perencanaan.

\section{Partisipasi Anggota P3A dalam Pelaksanaan Kegiatan Pengelolaan Air Desa Bandan Hurip dan Palas Jaya Kecamatan Palas Kabupaten Lampung Selatan}

Partisipasi anggota P3A dalam pelaksanaan dapat dinilai dari keikutsertaan petani dalam pelaksanaan pembangunan lokasi jaringan air irigasi, keikutsertaan petani anggota P3A dalam pelaksanaan pola tanam pada pengelolaan air irigasi, keikutsertaan petani anggota P3A dalam pelaksanaan penjadwalan atau pembagian air irigasi, keikutsertaan petani anggota P3A dalam pelaksanaan pemeliharaan jaringan irigasi. Partisipasi anggota P3A dalam pelaksanaan kegiatan diklasifikasikan dengan membagi menjadi tiga kelas yaitu rendah, sedang, tinggi.
Tabel.2. Partisipasi anggota P3A dalam tahap pelaksanaan

\begin{tabular}{ccccc}
\hline \multicolumn{2}{c}{ Selang } & Klasifikasi & $\begin{array}{c}\text { Jumlah } \\
\text { Anggota }\end{array}$ & Persentase \\
\hline 2,000 & 4,636 & Rendah & 37 & 45,12 \\
4,637 & 7,273 & Sedang & 31 & 37,80 \\
7,274 & 9,910 & Tinggi & 14 & 17,07 \\
\hline Jumlah & & & 82 & $100 \%$ \\
\hline
\end{tabular}

Tabel 2 menunjukan bahwa sebaran partisipasi petani anggota P3A dalam tahap pelaksanaan kegiatan pengelolaan air sebagian besar berada di kelasifikasi rendah yaitu sebesar 45,12 persen. Hal ini menunjukan bahwa sebagian besar responden anggota P3A memiliki tingkat partisipasi yang rendah pada tahap pelaksanaan kegiatan pengelolaan air, pada tahap pelaksanaan pembuatan lokasi jaringan air irigasi, responden anggota P3A tidak banyak terlibat dalam pelaksanaannya sebab hanya sebagian anggota yang dekat dengan pengurus yang di ajak untuk ikut serta dalam pembangunan saluran irigasi.

Pada tahap pelaksanaan pola tanam dan pelaksanaan penjadwalan atau pembagian air irigasi masih banyak responden anggota P3A yang tidak mematuhi penjadwalan pemberian air, dengan cara membuka pintu air secara diam - diam ini terjadi karena pengawasan yang kurang dari pengurus P3A. Pada pelaksanaan pemeliharaan jaringan irigasi responden anggota $\mathrm{P} 3 \mathrm{~A}$ masih bannyak yang belum mengikuti kegiatan pemeliharaan jaringan irigasi dengan alasan mengerjakan kegiatan lainnya seperti pekerjaan sampingan.

\section{Partisipasi Anggota P3A dalam Penilaian atau evaluasi Kegiatan Pengelolaan Air Desa Bandan Hurip dan Palas Jaya Kecamatan Palas Kabupaten Lampung Selatan}

Partisipasi anggota P3A dalam penilaian atau evaluasi dapat dinilai dari keikutsertaan petani anggota P3A dalam penilaian pembuatan lokasi jaringan irigasi, keikutsertaan petani anggota dalam penilaian atau evaluasi kegiatan pola tanam, keikutsertaan petani anggota P3A dalam penilaian atau evaluasi kegiatan pembagian atau penjadwalan pemberian air irigasi, keikutsertaan petani anggota P3A dalam penilaian atau evaluasi kegiatan pemeliharaan jaringan irigasi. Partisipasi anggota P3A dalam penilaian atau evaluasi kegiatan di kelasifikasikan dengan membagi menjadi tiga kelas yaitu rendah, sedang, tinggi. 
Tabel 3. Partisipassi anggota P3A dalam tahap penilaian atau evaluasi dalam pengelolaan air irigasi

\begin{tabular}{llccc}
\hline \multicolumn{2}{c}{ Selang } & Klasifikasi & $\begin{array}{c}\text { Jumlah } \\
\text { Anggota }\end{array}$ & Persentase \\
\hline 0,000 & 3,564 & Rendah & 51 & 62,19 \\
3,565 & 7,129 & Sedang & 14 & 17,07 \\
7,130 & 10,694 & Tinggi & 17 & 20,73 \\
\hline Jumlah & & 82 & $100 \%$ \\
\hline
\end{tabular}

Tabel 3 menunjukan bahwa sebaran partisipasi petani anggota $\mathrm{P} 3 \mathrm{~A}$ dalam tahap penilaian atau evaluasi kegiatan pengelolaan air sebagian besar berada di kelasifikasi rendah yaitu sebesar 62,19 persen. Hal ini menunjukan bahwa responden anggota P3A dalam tahap penilaian atau evaluasi rendah. Bentuk kegiatan penilaian atau evaluasi yaitu memeriksa kembali kegiatan yang telah terlaksana baik dari pelaksanaan pembuatan saluran irigasi, pelaksanaan pola tanam, penjadwalan pembagian air serta pelaksanaan pemeliharan irigasi, sudah terlaksana atau belum sesuai dengan perencanaan yang disepakati.

Rendahnnya tingkat partisipasi pada tahap penilaian atau evaluasi disebabkan oleh rendahnnya tingkat pengawasan petani anggota P3A terhadap jajaran pengurus P3A. Hanya sebagian kecil petani anggota P3A yang mengikuti proses penilaian atau evaluasi kegiatan pengelolaan air irigasi seperti jajaran pengurus. Rendahnnya tingkat partisipasi pada tahap penilaian atau evaluasi pengelolaan air juga disebabkan oleh kurangnnya pendampingan dari penyuluh dan pengurus $\mathrm{P} 3 \mathrm{~A}$.

Berdasarkan hasil penelitian tingkat partisipasi anggota P3A terhadap perencanaan, pelaksanaan, penilaian atau evaluasi kegiatan pengelolaan air irigasi di Desa Bandan Hurip dan Palas Jaya dapat disimpulkan tingkat partisipasi anggota P3A dalam pengelolaan air irigasi. Partisipasi anggota P3A dikelasifikasikan dengan membagi menjadi tiga kelas yaitu rendah, sedang, tinggi. Berikut tingkat partisipasi anggota P3A dalam pengelolaan air irigasi.

Tabel 4. Partisipasi anggota P3A dalam pengelolaan air irigasi

\begin{tabular}{ccccc}
\hline \multicolumn{2}{c}{ Selang } & Klasifikasi & $\begin{array}{c}\text { Jumlah } \\
\text { Anggota }\end{array}$ & Persentase \\
\hline 6,000 & 12,979 & rendah & 36 & 43,90 \\
12,980 & 19,959 & sedang & 22 & 26,82 \\
19,960 & 26,939 & tinggi & 24 & 29,26 \\
\hline Jumlah & & 82 & $100 \%$ \\
\hline
\end{tabular}

Berdasarkan Tabel 4 menunjukan bahwa sebagian besar partisipasi petani anggota P3A dalam pengelolaan air di Desa Bandan Hurip dan Palas Jaya berada pada klasifikasi rendah yaitu sebesar 43,90 persen. Hal ini menunjukan terdapat 43,90 persen tingkat partisipasi rendah yang harus di tingkatkan menjadi tingkat partisipasi sedang dan tinggi. Tingkat partisipasi responden anggota P3A dalam pengelolaan air di Desa Bandan Hurip dan Palas Jaya yang tergolong pada klasifikasi rendah.

Rendahnya tingkat partisipasi anggota P3A dalam pengelolaan air irigasi disebabkan oleh kurangnya pendampingan seperti sosialisasi dan ajakan yang dilakukan oleh penyuluh dan pengurus P3A terhada anggota P3A. Responden anggota P3A tidak banyak terlibat dalam kegiatan pelaksanaan pembangunan sebabhannya sebagian anggota yang dekat dengan pengurus yang diajak untuk ikut serta dalam pembangunan saluran irigasi, rendahnya pemahaman akan aturan dan kurangnnya sangsi yg diterima pelanggar berakibat banyaknya petani responden anggota $\mathrm{P} 3 \mathrm{~A}$ yang melanggar penjadwalan pembagian air.

\section{Analisis Variabel-Variabel yang Mempengaruhi Tingkat Partisipasi Anggota P3A dalam Pengelolaan Air Irigasi}

Variabel yang berpotensi mempengaruhi tingkat partisipasi anggota $\mathrm{P} 3 \mathrm{~A}$ dalam pengelolaan air irigasi terdiri dari interaksi anggota $\left(\mathrm{X}_{1}\right)$, keterlibatan anggota $\left(\mathrm{X}_{2}\right)$, tingkat pengetahuan anggota $\left(\mathrm{X}_{3}\right)$, motivasi anggota $\left(\mathrm{X}_{4}\right)$ dan keaktifan anggota P3A ( $\left.\mathrm{X}_{5}\right)$. Pengujian variabel-variabel yang mempengaruhi tingkat partisipasi anggota P3A dalam pengelolaan air irigasi di Desa Bandan Hurip dan Desa Palas Jaya dilakukan dengan analisis regresi logistik ordinal.

Regresi logistik ordinal juga menampilkan persentase pengaruh yang diberikan seluruh variabel bebas terhadap variabel terikat. Hal tersebut diketahui melalui nilai Pseudo $R$-Square. Berikut nilai Pseudo $R$-Square yang ditampilkan pada Tabel 5.

Tabel 5. Pseudo R-Square

\begin{tabular}{ll}
\hline Cox and Snell & 0,511 \\
Nagelkerke & 0,579 \\
McFadden & 0,333 \\
\hline Link function: Logit. & \\
\hline
\end{tabular}


Berdasarkan hasil analisis regresi logistik ordinal pada Tabel 5 dapat dilihat bahwa nilai LR index (Pseudo R-Square) sebesar 0,579. Nilai tersebut menjelaskan bahwa ada pengaruh antara variabel interaksi anggota $\left(\mathrm{X}_{1}\right)$, keterlibatan anggota $\left(\mathrm{X}_{2}\right)$, tingkat pengetahuan $\left(\mathrm{X}_{3}\right)$, motivasi anggota $\left(\mathrm{X}_{4}\right)$, interaksi anggota $\left(\mathrm{X}_{5}\right)$, dengan variabel tingkat partisipasi anggota $\mathrm{P} 3 \mathrm{~A}$ dalam pengelolaan air irigasi di Desa Bandan Hurip dan Palas Jaya (Y), sebesar 57,9 persen. Tingkat partisipasi anggota P3A dalam pengelolaan air di Desa Bandan Hurip dan Desa Palas Jaya dapat dijelaskan oleh variasi variabel independen $X_{1}$, sampai dengan $X_{5}$.

Sebannyak 42,1 persen perubahan tingkat partisipasi anggota P3A dalam pengelolaan air irigasi di Desa Bandan Hurip dan Palas Jaya dipengaruhi oleh variabel bebas lainnya yang tidak termasuk dalam model penelitian. Variabel bebas lainnya yang tidak termasuk dalam model dapat menjadi dasar bagi peneliti lain untuk mengembangkan kajian tentang tingkat partisipasi serta dapat meneliti lebih dalam terkait varibaelvariabel yang memengaruhi tingkat partisipasi anggota.

Pengaruh variabel terhadap tingkat partisipasi yang diolah dengan spss dapat dianalisis dengan melihat nilai signifikansi dan koefisien (parameter estimates). Persamaan model regresi variabelvariabel yang mempengaruhi tingkat partisipasi anggota P3A dalam pengelolaan air irigasi di Desa Bandan hurip dan Palas Jaya, yang terbentuk dapat dilihat dari hasil regresi logistik ordinal. Hasil regresi logistik ordinal variabel-variabel yang mempengaruhi tingkat partisipasi dalam pengelolaan air irigasi di Desa Bandan Hurip dan Palas Jaya dapat dilihat pada Tabel 6.

Tabel 6. Hasil regresi logistik ordinal variabel variabel yang mempengaruhi tingkat partisipasi dalam pengelolaan air irigasi

\begin{tabular}{lcc}
\hline \multicolumn{1}{c}{ Variabel } & Koefisien & Sig \\
\hline$[\mathrm{Y}=1]$ & 4,398 & 0,000 \\
{$[\mathrm{Y}=2]$} & 6,566 & 0,000 \\
Interaksi anggota $\left(\mathrm{X}_{1}\right)$ & 0,120 & 0,024 \\
Keterlibatan anggota $\left(\mathrm{X}_{2}\right)$ & 0,038 & 0,770 \\
Tingkat Pengetahuan & 0,205 & 0,130 \\
anggota $\left(\mathrm{X}_{3}\right)$ & 0,773 & 0,000 \\
Motivasi anggota $\left(\mathrm{X}_{4}\right)$ & 0,026 & 0,656 \\
Keaktifan anggota $\left(\mathrm{X}_{5}\right)$ & &
\end{tabular}

Persamaan hasil regresi yang terbentuk adalah sebagai berikut:

$$
\begin{aligned}
& \mathrm{Zi}=\operatorname{Ln}\left[\frac{\mathrm{pi}}{1-\mathrm{p}}\right]=4,398+0,120 \mathrm{X}_{1}+0,038 \mathrm{X}_{2}+0,205 \mathrm{X}_{3} \\
& +0,773 \mathrm{X}_{4}+0,026 \mathrm{X}_{5} \\
& \mathrm{Zi}=\operatorname{Ln}\left[\frac{\mathrm{pi}}{1-\mathrm{p}}\right]=6,566+0,120 \mathrm{X}_{1}+0,038 \mathrm{X}_{2}+0,205 \mathrm{X}_{3} \\
& +0,773 \mathrm{X}_{4}+0,026 \mathrm{X}_{5}
\end{aligned}
$$

Berdasarkan hasil analisis model ordinal logit pada Tabel 6, variabel bebas (independent) yang berpengaruh nyata yaitu interaksi anggota P3A $\left(\mathrm{X}_{1}\right)$, dan motivasi anggota $\left(\mathrm{X}_{4}\right)$.

\section{Interaksi Anggota}

Interaksi anggota merupakan proses komunikasi yang terjadi antar anggota, pengurus, penyuluh dan pihak lain dalam pengelolaan air irigasi. Berdasarkan hasil analisis regresi ordinal logit, variabel Interaksi anggota berpengaruh nyata terhadap tingkat partisipasi anggota P3A dalam pengelolaan air di Desa Bandan Hurip dan Desa Palas Jaya dengan tingkat kepercayaan sebesar 95 persen atau dengan tingkat siginifikasi sebesar 0,024 .

Tanda positif pada koefisien variabel partisipasi menunjukan bahwa pengaruhnnya berbanding lurus dengan tingkat partisipsi. Apabila frekuensi interaksi bertambah, dapat meningkatkan partisipasi petani. Ada pengaruh yang nyata antara variabel interaksi anggota dengan tingkat partisipasi anggota $\mathrm{P} 3 \mathrm{~A}$, yang berarti jika terdapat peningkatan interaksi anggota akan meningkatkan tingkat partisipasi sebesar 0,120 kali.

\section{Motivasi Anggota}

Motivasi anggota P3A merupakan suatu dorongan yang berasal dari dalam maupun luar diri anggota yang dapat menggerakan atau membangkitkan anggota kelompok agar mau mengikuti kegiatan pengelolaan P3A. Berdasarkan hasil analisis regresi ordinal logit, variabel motivasi anggota berpengaruh nyata terhadap tingkat partisipasi anggota P3A dalam pengelolaan air di Desa Bandan Hurip dan Desa Palas Jaya dengan tingkat kepercayaan sebesar 99,00 persen atau dengan tingkat siginifikasi sebesar 0,00 .

Tanda positif pada koefisien variabel motivasi anggota menunjukan bahwa pengaruhnnya berbanding lurus dengan tingkat partisipsi. Apabila motivasi anggota bertambah, dapat meningkatkan partisipasi petani. Ada pengaruh 
yang nyata antara variabel motivasi anggota dengan tingkat partisipasi anggota P3A, yang berarti jika terdapat peningkatan motivasi anggota maka akan meningkatkan tingkat partisipasi sebesar 0,773 kali.

Hasil ini sesuai dengan hasil penelitian Triana (2007) tentang partisipasi petani dalam program upaya khusus peningkatan produksi padi jagung dan kedelai (P2PJK) di Kecamatan Seputih Raman Kabupaten Lampung Tengah. Triana (2007) menyimpulkan bahwa terdapat pengaruh yang nyata antara tingkat motivasi petani dengan tingkat partisipasi petani terhadap suatu kegiatan. Kesamaan hasil penelitian tersebut memperkuat argumentasi tentang pengaruh yang nyata dari variabel motivasi terhadap tingkat partisipasi petani.

Hasil analisis regresi logistik ordinal menunjukkan bahwa variabel keterlibatan, tingkat pengetahuan dan keaktifan anggota tidak berpengaruh nyata terhadap tingkat partisipasi. Tidak terlihatnnya pengaruh variabel-variabel tersebut dapat disebabkan karna sampel yang diambil kemungkinan tidak cukup mewakili populasi anggota P3A yang ada di Desa Bandan Hurip dan Desa Palas Jaya. Ketidaktepatan penentuan sampel untuk meneliti kelima variabel bebas dapat menyebabkan hasil yang masih dapat dikaji. Kekurangan tersebut dapat menjadi landasan peneliti lainnya untuk menambah kajian baru tentang analisis tingkat partisipasi.

\section{Implikasi}

Hasil penelitian ini menunjukkan bahwa, sebannyak 43,90 persen petani anggota P3A dalam pengelolaan air di Desa Bandan Hurip dan Desa Palas Jaya berada pada tingkat partisipasi rendah. Partisipasi petani terbukti dipengaruhi oleh variabel interaksi dan variabel motivasi anggota. Upaya peningkatan partisipasi petani dalam pengelolaan air pada tahap perencanaan hingga evaluasi dapat dilakukan dengan memperbanyak interaksi dan motivasi. Interaksi dan motivasi anggota yang semakin bertambah dapat berdampak positif pada tingkat partisipasi yang lebih tinggi.

Interaksi anggota yang baik akan meningkatkan partisipasi anggota dalam melakukan suatu kegiatan sebab dipengaruhi oleh anggota lainnya. Frekuensi interaksi anggota dapat ditingkatkan melalui perencanaan penjadwalan pertemuan yang tepat, sehingga tujuan dalam interaksi dapat tercapai. Selain itu, pengambilan keputusan dalam struktur organisasi harus dijalankan dengan musyawarah untuk mufakat. Pengoptimalan sosialisasi oleh penyuluh dan pengurus P3A dalam pelaksanaan pengelolaan, pembangunan dan pendistribusian bantuan juga dapat dilakukan untuk meningkatkan kemauan dalam berinteraksi.

Motivasi anggota didasarkan atas kebutuhankebutuhan yang ingin didapatkan terhadap suatu program atau kegiatan. Motivasi anggota dapat ditingkatkan melalui pendekatan personal atau kelompok pengurus P3A. Pendekatan tersebut perlu dilakukan dengan menjelaskan manfaat yang diproleh apabila petanai berpartisipasi aktif dalam pengelolaan air. Penjelasan manfaat dapat dikrucutkan dengan perbandingan tingkat pendapatan petani yang berpartisipasi tinggi dan rendah. Dengan demikian, motivasi petani dalam pengelolaan air dapat bertambah.

\section{KESIMPULAN}

Tingkat partisipasi petani anggota P3A dalam pengelolaan air di Desa Bandan Hurip dan Palas Jaya berada pada klasifikasi rendah. Variabelvariabel yang mempengaruhi tingkat partisipasi petani anggota P3A dalam pengelolaan air di Desa Bandan Hurip dan Palas Jaya yaitu interaksi anggota P3A $\left(X_{1}\right)$ dan motivasi anggota $\left(X_{4}\right)$. Peningkatan interaksi anggota dalam partisipasi pengelolaan air dapat dilaksanakan melalui rencana penjadwalan kegiatan yang tepat, pengambilan keputusan dalam kelompok dilaksanakan dengan musyawarah untuk mufakat, pengoptimalan sosialisasi berupa penyuluhan baik formal maupun non formal yang dilakukan oleh kelompok dan penyuluh, mengikutsertakan seluruh anggota P3A dalam pelaksanaan pengelolaan air irigasi, baik proses pembangunan ataupun pendistribusian bantuan yang didapat oleh kelompok P3A. Peningkatkan motivasi anggota dalam partisipasi pengelolaan air dapat dilaksanakan melalui transparansi pengurus kelompok serta pengoptimalan tugas pengurus kelompok P3A

\section{DAFTAR PUSTAKA}

Antika AY, Nikmatullah D, Prayitno RT, 2017. Tingkat partisipasi anggota P3A dalam program Pengembangan Jaringan Irigasi (PJI) di Kelurahan Fajar Esuk Kecamatan Prengsewu Kabupaten Pringsewu. Jurnal Ilmu Ilmu Agribisnis, 5(3): 335-343.

Badan Pusat Statistik Provinsi Lampung. 2018. Produksi Padi Per Kabupaten/Kota di 
Provinsi Lampung. Badan Pusat Statistik. Jakarta Pusat.

Badan Pusat Statistik Lampung Selatan. 2018. Luas Panen, Produksi dan Produktivitas Padi Per Kecamatan. Badan Pusat Statistik. Jakarta Pusat.

Badan Pusat Statistik Provinsi Lampung. 2018. Data Produksi Padi di Provinsi Lampung. Badan Pusat Statistik. Jakarta Pusat.

Balai Penyuluhan Pertanian Kecamatan Palas. 2017. Data Luas Lahan dan Jenis Sawah Per Desa. Kecamatan Palas Kabupaten Lampung Selatan.

Hafif B. 2016. Optimasi potensi lahan kering untuk pencapaian target peningkatan produksi padi satu juta ton di Provinsi Lampung. Jurnal Litbang Pertanian. Vol. 35 ( 2 ):81-88.

Ibrahim, Wangke, dan Memah. 2017. Partisipasi anggota P3A dalam pemeliharaan jaringan irigasi. Jurnal Agri-sosial Ekonomi. Unsrat. Vol. 13 ( 2 ):219-228.
Ndraha T. 1990. Pembangunan Masyarakat. PT. Rineka Cipta. Jakarta.

Peraturan Pemerintah Republik Indonesia No.20.2006. Irigasi. Departemen Pekerjaan Umum. Jakarta.

Taufik M, Arafah, Nappu B, dan Fadjry D. 2014. Analisis pengelolaan air dalam usaha tani padi pada lahan sawah irigasi di Sulawesi Selatan. Jurnal Pengkajian dan Pengembangan Teknologi Pertanian. Vol 17 ( 1 ): 61-68.

Triana R S. 2007. Partisipasi Petani Dalam Program Upaya Khusus Peningkatan Produksi Padi Jagung dan Kedelai (P2PJK) di Kecamatan Seputih Raman Kabupaten Lampung Tengah. Skripsi. Jurusan Agribisnis Fakultas Pertanian Universitas Lampung.

Widarjono A. 2010. Analisis Multivarial Terapan. Unit penerbit dan percetakan Sekolah Tinggi Ilmu Menejemen Yayasan Keluarga Pahlawan Negara. Yogyakarta. 